\title{
Ambiente de qualidade em uma biblioteca universitária: aplicação do 5 S e de um estilo participativo de administração
}

Nadia Vanti

\section{Resumo}

O artigo divide-se em duas partes. A primeira analisa o Programa $5 S$ de administração, nascido no Japão no final da década de 60, e o estilo participativo de gerenciamento organizacional. A segunda parte apresenta, a partir desta análise, uma experiência de aplicação conjunta destas duas formas de gestão em uma biblioteca universitária. Procura-se demonstrar que é possível, em um contexto de recursos escassos, encontrar soluções originais, alcançando significativa melhoria na prestação dos serviços aos usuários e criando um clima de confiança, responsabilidade e qualidade no local de trabalho.

Palavras-chave

Programa 5S; Gestão participativa; Ambiente de qualidade; Administração de bibliotecas; Biblioteca universitária.

\section{INTRODUÇÃO}

A busca por um ambiente de qualidade é uma preocupação cada vez mais freqüente dos administradores para atingir os objetivos das organizações que presidem de forma eficiente. $O$ estilo norte-americano, voltado exclusivamente para a organização, estaria ultrapassado, cedendo lugar a outras maneiras de administração, mais centradas nas relações humanas. A biblioteca, como uma organização sem fins lucrativos, porém com objetivos bem definidos como a prestação de serviços de informação e $o$ atendimento ao usuário, não poderia deixar de estar atenta às novas formas de gerenciamento e filosofias organizacionais.

Entre estas filosofias, encontra-se 0 movimento dos 5S, nascido no Japão no final da década de 60 , quando pais ensinavam a seus filhos princípios educacionais que os acompanhariam até a fase adulta. Nas organizações, o desenvolvimento deste programatem por finalidade aprimorar o ambiente de trabalho, gerar estímulos para relacionamentos mais humanos e melhorar a qualidade de vida dos funcionários.

Outra modalidade de gerenciamento que também vem ganhando espaço nos últimos anos é a administração democrática e participativa. Esta forma de gestão procura o completo envolvimento das pessoas na tomada de decisões, tornando-as mais comprometidas e responsáveis pelos rumos da organização na qual trabalham. Constituindo-se, assim, em um estilo dinâmico e aberto que cria oportunidades, libera potencialidades e estimula a iniciativa pessoal.

As unidades de informação, devido à necessidade de estarem constantemente em mudança, incorporando novas tecnologias e procurando tornaremse cada vez mais atrativas e essenciais para seus usuários, constituemse em ambientes propícios para estas novas formas de gestão. Os dirigentes destas unidades, em sintonia com as modificações de paradigmas administrativos que estão se produzindo no mundo, enfrentam o desafio de adequarem-se a tais mudanças, visando à melhoria da qualidade dos serviços que prestam a sua comunidade de usuários.

O PROGRAMA 5 S E A GESTÃO 


\section{PARTICIPATIVA}

\section{Programa 5S}

Os cinco sensos que dão nome ao Programa 5S têm sua origem nas iniciais das palavras japonesas seiri, seiton, seiso, seiketsu, shitsuke. Em português são conhecidos como os sensos de utilização, organização, limpeza, saúde e autodisciplina. O 5 S é um sistema organizador, mobilizador e transformador de pessoas e organizações. Assim como as filosofias do justin-time (no tempo certo), kaizen (meIhoria contínua), controle de qualidade total, jidoka(autodetecção) e manutenção produtiva total, o 5 S também aponta para a melhoria do desempenho global da organização (Masiero) ${ }^{1}$. De acordo com Silva² (p.23), "o 5 S deve ser implementado com o objetivo específico de melhorar as condições de trabaIho e criar o ambiente de qualidade". Encaminha-se para um espaço de trabalho limpo e bem organizado e é prévio a qualquer outra inovação que objetive melhorar as condições de trabalho e a qualidade dos produtos e serviços, envolvendo o quotidiano de toda organização.

A satisfação do cliente, qualidade, segurança, motivação e a economia de recursos escassos são as metas principais deste programa. Propõe criar as condições básicas ao desenvolvimento de organizações responsáveis socialmente, sem perder de vista o seu objetivo principal, seja este o lucro ou a utilização plena dos seus recursos. De acordo com Campos ${ }^{3}$ (p.28), "o 5S promove o aculturamento das pessoas a um ambiente de economia, organização, limpeza, higiene e disciplina, fatores fundamentais à elevada produtividade".

A motivação coletiva é um conceitochave neste sistema. Motivar as pessoas para a ação, para agir com entusiasmo e para comprometer-se dando o melhor de si são requisitos fundamentais para alcançar a qualidade total. Como afirma Silva² (p.23), "somente quando os empregados se sentirem orgulhosos por terem construído um local de trabalho digno e se dispuserem a melhorá-lo constantemente, terse-á compreendido a verdadeira essência do 5S".
Os objetivos centrais do processo 5S consistem em melhorar o ambiente de trabalho, promovendo o bem-estar dos funcionários e aumentando sua autoestima; racionalizar o uso de documentos, materiais e equipamentos; reduzir custos e agilizar os processos de trabalho; facilitar a participação de todos e o inter-relacionamento pessoal, estimulando a execução de tarefas em equipe, e contribuir para a melhoria da imagem da instituição (Osada ${ }^{4}$, Ribeiro $^{5}$, Rosa e Bolson ${ }^{6}$ ). Para atingir estes objetivos, o programa firma-se nos cinco sensos já mencionados, a serem examinados a seguir.

O senso de utilização, segundo Silva ${ }^{2}$ e Prazeres ${ }^{7}$, favorece a eliminação do desperdício de inteligência, tempo e matéria-prima. Significa usar os recursos disponíveis, com bom senso e equilíbrio, evitando desatualizações e carências. Todos os funcionários devem identificar e manter no seu lugar os itens verdadeiramente úteis ao seu serviço. Ribeiro ${ }^{5}$, assim como Osada ${ }^{4}$, denominam este primeiro senso, senso de organização, enfatizando o objetivo de separar as coisas necessárias das desnecessárias a partir de critérios de estratificação, classificando os objetos segundo a ordem de importância.

O senso de ordenação, para Silva ${ }^{2}$ (p.41-42), facilita o desenvolvimento do primeiro senso, ao diminuir o tempo de busca dos objetos. Implica "dispor os recursos de forma sistemática e estabelecer um excelente sistema de comunicação visual para o rápido acesso a eles". Para Prazeres ${ }^{7}$, este senso consiste em dar lugar a cada item e colocar cada item em seu lugar, padronizando as nomenclaturas e evitando, assim, mais de uma interpretação para o mesmo objeto. Segundo Osa$\mathrm{da}^{4}$ (p.27-28), este senso, denominado por ele princípio de arrumação, "significa colocar as coisas nos lugares certos ou dispostas de forma correta para que possam ser usadas prontamente. É uma forma de acabar com a procura de objetos". Enfatiza o gerenciamento funcional e permite que se encontre 0 que se precisa quando se quer. Busca formular regras claras que governem a estratificação, permitindo um leiaute flexível que possa ser alterado, de ma- neira a impedir a formação de labirintos e aumentar a eficiência.

O senso de limpeza, de acordo com todos os autores mencionados, pode ser definido como a eliminação da sujeira sob todos os aspectos, incluindo a boa preservação dos equipamentos, ambiente de trabalho limpo, com agradável sensação de bem-estar e eliminação de estoques desnecessários. Pode ser feita pelos próprios funcionários, cada um tornando-se responsável pela manutenção de seu espaço. A limpeza é considerada uma oportunidade para o monitoramento, inspeção ou reconhecimento do local de trabalho, permitindo descobrir e atacar as causas da sujeira e facilitando, desta forma, a criação de um ambiente impecável (Silva², Prazeres $^{7}$, Osada $^{4}$, Ribeiro ${ }^{5}$.

O quarto senso é denominado de formas diferentes segundo os diversos autores citados: senso da saúde, higieneou padronização. Silva ${ }^{2}$ considera que este refere-se ao estágio alcançado com a prática dos três sensos anteriores, acrescido de hábitos rotineiros de higiene, segurança no trabalho e saúde mental. Segundo ele, excesso de materiais, má ordenação e sujeira são, reconhecidamente, causas de acidentes de trabalho e estresse. Combater essas causas já significa grande iniciativa para conservar a vida da empresa e dos empregados em boas condições. Para Ribeiro ${ }^{5}$, o seiketsu é traduzido como asseio, o que implica conservar a higiene, sem descuidar os estágios de organização, ordem e limpeza alcançados, padronizando hábitos, normas e procedimentos. Já para Osada ${ }^{4}$ (p.31), este quarto senso consiste na padronização, objetivando manter a organização, a arrumação e a limpeza contínua e constantemente. Enfatiza o gerenciamento visual, a manutenção das condições-padrão, permitindo agir com rapidez.

O quinto e último senso, o senso de disciplina, procura a manutenção da nova ordem estabelecida. Implica cumprir rigorosamente as normas e tudo aquilo que for decidido pelo grupo. Con- 
sidera-se a disciplina como um sinal de respeito aos outros. À medida que as pessoas se mantêm comprometidas com o fiel cumprimento dos padrões técnicos e éticos, é produzida uma evidente melhoria individual e organizacional. Este último senso apregoa a luta permanente para manter e melhorar os quatro sensos anteriores e a capacidade de fazer as coisas como devem ser feitas, demonstrando como, em definitivo, os cinco sensos estão interligados (Silva², Ribei$\mathrm{ro}^{5}, \mathrm{Osada}^{4}$ ).

\section{Gestão participativa}

A gestão participativa caracteriza-se por uma administração profundamente democrática, permitindo aos membros de toda organização manifestar suas opiniões em relação aos caminhos a serem seguidos. Esta forma de gerenciar representa o estilo moderno de administração que Chiavenato ${ }^{8}$ identifica com as seguintes características em relação à natureza do ser humano: as pessoas não necessariamente sentem desprazer em trabalhar, o trabalho pode ser fonte de grandes satisfações, as pessoas contam com motivação individual e ambições e ainda são capazes de assumir novas responsabilidades e desafios.

Este estilo de administração prioriza a tomada de decisões por consenso, procurando contemplar todas as opiniões e pontos de vista dos integrantes de uma equipe de trabalho. Para isto, estimula a exposição constante de razões, argumentos, críticas, sugestões e idéias por parte de todos os membros, inclusive dos mais introvertidos. Esta proposta busca um permanente envolvimento mental e emocional, apontando para a motivação e a assunção de maiores responsabilidades por parte dos integrantes do grupo. Pressupõe ampla liberdade de ação e pensamento, tanto nos relacionamentos humanos dentro do local de trabalho, quanto na forma de levar a cabo as diversas tarefas. Como destaca Silva², é imprescindível criar um clima de seriedade, mas também de absoluta democracia, em que todos tenham oportunidade de expressão e predominem atitudes que favoreçam o trabalho em equipe. Isto implicaria deixar para trás o sistema taylorista, que resulta em uma organização do trabalho extremamente autoritária.

Segundo assevera Kanaane ${ }^{9}$ (p.21), "as organizações necessitam adotar posturas mais flexíveis com relação às concepções sobre poder e influência, o que implica a adoção de estratégias compatíveis com o envolvimento e o engajamento dos trabalhadores, possibilitando a valorização do potencial humano".

O gerente que se propõe a dar um enfoque mais humano ao seu estilo de administração deve sempre tentar criar melhores condições de trabalho e um ambiente psicológico mais favorável, melhor qualidade de vida para os funcionários, assegurando, desta forma, produtividade mais elevada, melhor relacionamento interpessoal e maior satisfação por parte do cliente ou usuário. Deve procurar, outrossim, evitar a superespecialização e a rotinização de tarefas, ampliando e diversificando os cargos e multiplicando a gama de atividades, para que todos possam entender melhor o que fazem e perceber a sua contribuição individual no processo geral de trabalho. Masiero ${ }^{1}$ assinala que cabe ao chefe atuar como facilitador e assumir o papel de líder social, criando um clima favorável na organização que preside ou administra.

Como destaca este último autor, "o princípio básico da Administração Participativa é valorizar e respeitar o trabalhador enquanto ser humano, como fundamental para a condução dos negócios, e não simplesmente um componente da estrutura produtiva como uma máquina qualquer" (Masiero ${ }^{1}$, p.111).

Em uma gestão participativa, a comunicação fluida entre os integrantes do grupo de trabalho e seu condutor é fundamental. Sem comunicação, é difícil manter um bom desempenho em equipe. Todas as decisões devem sujeitarse à ratificação dos trabalhadores envolvidos, ampliando, para isto, os canais de comunicação, enfatizando o aspecto humano e gerando situações estimuladoras. Em um processo com estas caraterísticas, o estilo de liderança é determinante para o grau de sucesso que possa ser alcançado. Um bom administrador há de saber condu- zir as pessoas e administrar as diferenças entre elas de forma democrática, comunicativa, justa e não-arbitrária, preocupando-se com as questões humanas dos membros da equipe (Kanaane $^{9}$, Chiavenato ${ }^{8}$, Alencar $^{10}$ ).

Outro aspecto de extrema importância a ser considerado para a obtenção de sucesso em uma administração participativa é a motivação. Além de uma liderança eficaz, faz-se necessária uma contínua motivação da equipe, atuando como dinamizadora do comportamento humano, a partir de uma ênfase na liberdade pessoal, valorização da criatividade inovadora e reafirmação do senso de responsabilidade individual $\left(\right.$ Chiavenato $\left.{ }^{8}\right)$. Como ressalta Alencar ${ }^{10}$ (p. 25), no mesmo sentido, "a motivação é considerada o componente mais importante tanto no âmbito do indivíduo quanto da organização. Embora sejam recursos e competências de gerenciamento que tornam a inovação possível, a motivação é o elemento catalisador das ações voltadas para a inovação".

Em síntese, o administrador que possibilite que cada um assuma a gestão do seu próprio tempo, torne as tarefas compatíveis com as habilidades de cada um, estimule processos empáticos, gerencie de forma amigável e fomente a participação dos funcionários nas decisões - propiciando a responsabilidade pelos resultados, orguIho e reconhecimento de todos -, estará, de alguma maneira, contribuindo para a melhoria contínua do contexto social de trabalho e da redução da alienação. Todos estes elementos configuram a essência da gestão participativa e democrática, tão necessária na conjuntura social e econômica em que se encontram as organizações no limiar do século XXI.

\section{APLICAÇÃO EM UMA BIBLIOTECA UNIVERSITÁRIA}

Pretende-se relatar, nesta seção, a experiência de aplicação em uma biblioteca universitária das duas formas de administração organizacional des- 
critas nas páginas precedentes. Concretamente, examinar-se-á quais têm sido os resultados da implementação prática destes estilos gerenciais na Biblioteca da Faculdade de Veterinária da Universidade Federal do Rio Grande do Sul (UFRGS), onde desempenhei a função de bibliotecária-chefe de abril de 1997 a março de 1999.

A Biblioteca de Veterinária 'Desidério Finamor' foi fundada em 1962 e se destina a ser suporte de informação para o ensino, pesquisa e extensão do Curso de Medicina Veterinária da UFRGS. Seu acervo é composto, aproximadamente, por 5000 livros, 1900 folhetos, 130 títulos de periódicos correntes e 280 não correntes, 33 fitas de vídeo, 12 fitas-cassete e uma base de dados em CD-ROM. Possui uma área física de $164 \mathrm{~m}^{2}$ no total, divididos entre hall de entrada, sala de processamento técnico, sala da chefia e um espaço único para o acervo e consulta ao material bibliográfico (composto de cinco mesas para trabalhos em grupo, sete individuais e 32 assentos para leitura). Os usuários da biblioteca são os alunos matriculados na graduação (1751) e pós-graduação (95), professores e funcionários. Em relação aos recursos humanos, a biblioteca conta com um chefe, quatro funcionários permanentes e um bolsista*.

Ao assumir a administração da biblioteca, procurei desempenhar um papel empreendedor, incorporando idéias de inovação, mudança e criatividade, visando a modificar o ambiente organizacional e melhorar os serviços de informação oferecidos. Como bem salienta Dias ${ }^{11}$ (p.19), são características fundamentais no papel do empreendedor... planejar e implementar mudanças do serviço, estimular mudanças, resolver problemas através da introdução de mudanças, identificar melhorias que possam ser introduzidas no serviço. Acompanhar as mudanças advindas com o surgimento das novas tecnologias também faz parte de uma visão empreendedora na gestão de uma unidade de informação.

Um mês após o início da gestão como chefe da biblioteca, ao ser convidada a fazer um curso de $5 \mathrm{~S}$ oferecido pelo

\footnotetext{
* Dados correspondentes ao ano de 1998.
}

Sistema de Bibliotecas da UFRGS, aprendi, na teoria, a filosofia do $5 \mathrm{~S}$ e os princípios que norteiam sua aplicação. Considerei que seria de suma utilidade, naquele momento, sua implementação na Biblioteca da Veterinária.

Antes de efetuar qualquer aplicação do Programa 5S, foi feito um diagnóstico da situação inicial da biblioteca, a fim de detectar os principais problemas, suas causas, possíveis soluções, conhecer melhor os recursos disponíveis e estabelecer certas prioridades. Quando se pretende reorganizar uma biblioteca, como postula Maciel ${ }^{12}$ (p.20), a primeira fase a ser cumprida é o conhecimento minucioso da organização que apresenta... problemas em todos os seus setores, serviços, rotinas e recursos e, após este levantamento, a análise dos dados obtidos para o conseqüente estabelecimento das causas reais e das falhas estruturais que os ocasionaram.

De tal forma, buscou-se avaliar, mesmo que informalmente e de maneira nem sempre sistemática, como teria sido desejável, o nível de satisfação dos usuários e funcionários da unidade. Partiu-se do pressuposto de que era fundamental, como explica Silva ${ }^{2}$, levar em conta as condições preexistentes para não traumatizar as pessoas com as mudanças a serem realizadas.

Após o diagnóstico, a primeira atitude foi realizar uma limpeza geral - pré-requisito para a implementação do Programa 5S - que permitiu a verificação dos problemas mais sérios. A aplicação deste Programa na Biblioteca da Veterinária foi quase que intuitiva, pois pessoalmente tenho por hábito fazer muitas coisas que o programa sugere, porém foi necessário transmitir aos colegas estes conceitos para conseguir que todos colaborassem na criação de um verdadeiro ambiente de qualidade.

Discordando em parte com o que sugerem alguns autores, para os quais usar e divulgar a nomenclatura 5S seria um elemento fundamental para atingir o sucesso, neste caso não foi realizada uma campanha explícita para a aplicação do Programa. Procurou-se gerar entusiasmo e sensibilizar as pessoas da forma mais natural e espontâ- nea possível, com objetivo de estimular a capacidade de autoditatismo de cada um, apontando para a realização de resultados visíveis e concretos.

Tentou-se produzir melhorias imediatas dentro das limitações orçamentárias e de pessoal que tínhamos, em relação a questões que vinham sendo reivindicadas pelos usuários e pelos próprios funcionários há algum tempo. Com um melhor e mais imaginativo uso dos recursos existentes, conseguiram-se alguns resultados que serviram para motivar e mobilizar a equipe. No decorrer desta gratificante experiência, percebeu-se que é fundamental educar dando o exemplo, mediante real comprometimento com as ações do coletivo, ganhando assim credibilidade, e também ressaltar, constantemente, a importância da contribuição dos funcionários. Desta maneira, começou um processo de melhoria contínua no funcionamento da biblioteca.

No que se refere ao senso de utilização, procurou-se descartar todo aquele material bibliográfico desatualizado e que não estava sequer processado. Nos casos em que havia dúvidas quanto à sua utilidade, pediu-se a opinião dos professores especialistas no assunto para avaliá-los e, quando eram realmente considerados importantes, foram incorporados ao acervo. Materiais em outros idiomas que jamais haviam sido consultados, como em alemão antigo, foram repassados ao professor que possuía conhecimento deste idioma e tinha interesse no assunto. Dissertações e teses em duplicata foram colocadas no depósito. Ao descartar material que não servia, conseguimos ganhar espaço para aquilo que realmente interessava e era de maior valor para o usuário. Tentamos justificar a utilidade de cada item, o que não podia ser justificado foi eliminado da biblioteca.

Seguindo a Osada (p. 45), o senso de utilização (seiri) é realmente a arte de eliminar as coisas desnecessárias. Considerou-se importante, na biblioteca, saber o que eliminar e o que guardar (e quanto), estabelecendo a estratificação dos materiais por ordem de importância, a partir do qual foi determinado o que conservaríamos e o que descartaríamos e onde colocaríamos cada coisa. Orientaram-se os funcio- 
nários para que eles próprios pudessem avaliar a importância de cada item e poder decidir o que fazer, com vistas a evitar que adotassem a idéia do simples descarte, ao invés da concepção da plena e efetiva utilização dos recursos existentes. Equipamentos que estavam encostados dentro de armários foram encaminhados para o Departamento de Patrimônio da Universidade, ou, quando houve possibilidade, consertados e colocados novamente em uso. Em definitivo, foi feito um remanejamento dos recursos não utilizados, com o propósito de evitar o desperdício.

No que diz respeito ao senso de ordenação, modificamos o leiaute da biblioteca com a perspectiva de aproveitar melhor o espaço, para ampliar as possibilidades de circulação dos funcionários e usuários, facilitar a limpeza e o controle de entrada e saída de pessoas e material de empréstimo. A localização dos móveis e materiais foi disposta de acordo com a freqüência de uso. Tentou-se definir um lugar para cada coisa, criando assim regras de arrumação. Procurou-se guardar as coisas em locais onde posteriormente pudessem ser achadas com maior facilidade e menor perda de tempo.

O ambiente destinado à exposição de periódicos foi trocado para um local mais próximo à entrada da Biblioteca, possibilitando melhor visualização e aumentando a freqüência de uso daquele espaço. Além disso, dissertações, teses e fitas de vídeo, que estavam guardadas no setor interno da biblioteca, foram expostas junto ao restante do acervo para que pudessem ser encontradas mais facilmente pelo usuário. Os relatórios, que estavam colocados nas estantes, amarrados com cordão por ordem cronológica, foram mudados para um lugar mais próximo das dissertações e teses e dispostos com a mesma ordenação destas últimas (alfabética por autor).

Havia, outrossim, documentos internos da biblioteca e folhetos para consulta dos usuários em um só arquivo, já sem espaço. Foi solicitado um segundo arquivo para separar material interno e externo e ter, desta maneira, distintos materiais em locais diferentes, proporcionando maior comodidade tanto para os funcionários quanto para os usuários. Por outro lado, foi reforçada a sinalização visual em diferentes lugares da biblioteca: nas estantes, no setor de empréstimo, de referência etc., facilitando a orientação. Mudou-se, também, o setor de empréstimo para um ponto mais estratégico e adquiriu-se um balcão - na biblioteca ainda não existia balcão de empréstimo, contávamos apenas com uma pequena mesa para o funcionário realizar esta tarefa.

Quanto ao senso de limpeza, a primeira providência foi distribuir recipientes de coleta de lixo nos diferentes locais da biblioteca, estimulando as pessoas a não jogarem papéis no chão. Também foram forradas pequenas estantes que estavam enferrujadas, colocando sobre elas vasos coloridos e de tamanho padronizado com violetas, tornando o ambiente mais agradável.

Um dos funcionários sugeriu a limpeza dos vidros internos da biblioteca, cada um encarregando-se de sua parte, o que nos motivou ainda mais a criar e manter um ambiente físico agradável. Mediante a conscientização de que cada um é responsável pela limpeza de sua própria área de trabalho, possibilitou-se o entendimento das vantagens de não sujar. Foi solicitado ao pessoal de limpeza da universidade, no mesmo sentido, que encerassem o chão com maior freqüência, causando uma boa impressão de asseio e brilho aos olhos dos usuários e visitantes.

Houve, ainda, um movimento cooperativo para a pintura das paredes: um funcionário da biblioteca se dispôs a pintar, o diretor da Faculdade providenciou a tinta, e o restante da equipe ajudou na pintura das portas e janelas e limpou a sujeira produzida na realização de tal tarefa. Este exemplo da pintura serviu, também, como excelente oportunidade para reforçar ainda mais a união dos integrantes da equipe em torno de objetivos comuns. Desta forma, o grupo sentiu-se orgulhoso por construir e trabalhar em um lugar limpo, e os próprios usuários demonstraram maior prazer em permanecer na biblioteca. Um ambiente limpo, claro, tranqüilo e com bom aspecto atrai muito mais às pessoas.

O senso de padronização, saúde ou higiene resultou da estandardização de certos comportamentos e da instauração de controles visuais, facilitando a detecção de anormalidades. Foi implantada a 'carteirinha' da biblioteca para fiscalizar melhor a saída e retorno do material bibliográfico para empréstimo e criado um registro para o controle dos periódicos retirados para cópia. Por outro lado, houve uma preocupação da equipe com a manutenção de uma iluminação adequada na biblioteca, trocando as lâmpadas queimadas para não prejudicar a visão tanto de funcionários quanto de usuários no trabalho ou pesquisa.

Visando a melhorar a organização das instalações e a comodidade dos usuários, adquiriu-se mais um armário de aço para que estes pudessem deixar seus pertences guardados antes de entrar na biblioteca. Além disso, seguindo a sugestão de um dos professores da Faculdade, foi confeccionado um armário de madeira com portas de vidro para a exposição das obras raras que estavam atiradas num canto pegando pó, permitindo assim que estas fossem notadas e valorizadas por todos.

Procurou-se, na medida do possível, eliminar as causas de acidentes de trabalho e estresse, com o objetivo de manter a saúde física, mental e emocional dos integrantes da equipe. Apoiando, em conseqüência, a realização de controles médicos e a prática de esportes. No mesmo sentido, buscouse distribuir as tarefas de forma racional e estimular um clima de confiança, amizade e solidariedade entre todos nós. As reuniões-almoço para confraternização e discussão dos problemas tornaram-se uma constante em nosso trabalho.

Por último, no que se refere ao senso de disciplina, considerando que este é fundamental para a cooperação na equipe, procurou-se que cada um conseguisse internalizar as regras de forma espontânea, sem coerção. A geração de bons hábitos é chave para o bom desenvolvimento do trabalho de toda a equipe, junto à plena aplicação dos quatro sensos anteriores. Cada funcionário foi tomando consciência das tarefas que devia desempenhar e assumindo pouco a pouco mais responsabilidade pessoal por suas atividades. 
Para ajudar neste processo, valorizouse a utilização do painel já existente, destinado à exposição de cartazes com informações de cursos, congressos e seminários na área de veterinária, atualizados diariamente por um membro da equipe que se propôs a responsabilizar-se por tal tarefa. Foi criado, por outra parte, um quadro para recados, onde os funcionários podiam fixar avisos para os colegas ou para os usuários da Biblioteca. Houve, enfim, uma mudança na mentalidade do grupo e na percepção que tínhamos da organização, favorecendo a autodisplina e o autocontrole, sempre levando em consideração as possibilidades e capacidades de cada um.

Associado ao Programa 5S, adotou-se uma decidida política de plena participação do conjunto dos funcionários na gestão da biblioteca. No início, houve alguma resistência de todos fazerem tudo, mas aos poucos fomos entendendo que era necessária a contribuição de cada um em todas as tarefas para a melhoria do processo. Muitas pessoas não estão preparadas para uma gestão democrática, ficando desconcertadas quando são consultadas e têm de participar na tomada de decisões, ou não sabem como agir quando devem decidir por si mesmas, tamanho o peso das regras autoritárias com que fomos socializados desde a infância.

Ao implementar procedimentos da democracia consensual, favoreceu-se a discussão e negociação intensas, procurando contemplar os desejos, opiniões e aspirações de todos. Buscou-se compartilhar missão, visão e princípios, melhorar a comunicação e indicar maiores responsabilidades a cada um, fazendo com que as pessoas se sentissem responsáveis pelas decisões e ações realizadas. Recorreu-se constantemente ao diálogo, mecanismo que, segundo Chiavenato ${ }^{8}$, auxilia a administrar e superar melhor os conflitos, possibilitando, desta forma, extrair resultados positivos, e descobrindo maneiras criativas e inovadoras de realizar as tarefas.

Concordando também com Alencar ${ }^{10}$ (p. 25), "é necessário que uma plataforma para a criatividade individual esteja presente no ambiente das organi- zações. Essa plataforma tem como base a presença de sentimento de confiança e respeito à harmonia nas equipes, a prática das virtudes de compartilhar idéias, respeitar as diferenças, valorizar o trabalho do indivíduo e do grupo, reconhecer as potencialidades e oferecer oportunidades para a produção e fertilização de idéias".

Encontros de confraternização como forma de integrar a equipe e melhorar o relacionamento interpessoal foram bastante freqüentes na Biblioteca. Como foi já exposto em páginas anteriores, este tipo de reuniões contribuiu para o maior envolvimento de todos na melhoria do ambiente de trabalho, maior confiança e disposição para enfrentar os desafios do dia-a-dia. Assuntos que poderiam ter sido desmotivadores em outro contexto, como os baixos salários, por exemplo, foram mais um fator de união entre todos, ao envolver-nos e participar de forma ativa nos movimentos de protesto por melhorias salariais organizados pelo sindicato da categoria no primeiro semestre de 1998.

Cabe ressaltar que certas circunstâncias facilitaram bastante a implementação destes novos estilos gerenciais, pois sabe-se que é mais factível obter sucesso num processo de mudanças como o experimentado, para alguém que provém de fora da organização, como bem destaca Silva ${ }^{2}$. Audácia e sinal verde de cima, para produzir as transformações, também foram fatores determinantes do sucesso alcançado. $\mathrm{E}$, logicamente, todo o processo foi mais fácil ainda em se tratando de um grupo reduzido de funcionários.

Solicitou-se sempre a opinião dos integrantes da equipe, pedindo a cada um que dissesse o que poderia fazer para melhorar seu desempenho e o funcionamento do conjunto, visando a melhorar o atendimento do usuário. Olhamos criticamente para o lugar onde estávamos trabalhando e discutimos que modificações poderíamos realizar para facilitar a vida de todos nós, e fomos avaliando os avanços que íamos conseguindo. Ao fomentar o desenvolvimento de nossos melhores atributos pessoais, a mobilização deu-se mais pelo prazer do que pelo dever, eliminando hierarquias rígidas e flexibilizando as relações entre o chefe e o resto da equipe.

Em síntese, estas mudanças causaram um forte impacto e contribuíram de forma fundamental na motivação do grupo. Como coordenadora, tentei sempre demonstrar um verdadeiro comprometimento pessoal com a realização das mudanças, com o objetivo de dar um bom exemplo. Para uma gestão participativa, é fundamental haver coerência entre discurso e ação. A equipe da biblioteca, ao receber visitas externas e elogios por parte de funcionários de outros setores, dos professores e do diretor da Faculdade, sentiu-se altamente estimulada, o que proporcionou uma renovada motivação e foi razão de orgulho para todos nós.

\section{CONCLUSÃO}

Ficou claro, com esta experiência de administração na Biblioteca de Veterinária da UFRGS, que é possível, com a aplicação do $5 \mathrm{~S}$ associado a um estilo participativo de gestão, encontrar soluções originais para os problemas mais urgentes em um contexto de recursos escassos. Conseguiu-se alcançar substancial melhoria na prestação dos serviços e criar um clima de confiança, autodisciplina e responsabilidade que resultaram em um ambiente de qualidade no local de trabalho. Percebeu-se aumento na motivação e coesão grupal, conscientização dos integrantes da equipe, despertar da alegria, maior interesse e boa vontade no desempenho das diversas tarefas. Notouse, principalmente, a diferença em gerenciar com as pessoas e não as pessoas. O espírito crítico, quando adequadamente aproveitado e canalizado, pode contribuir para o crescimento da organização.

Estas transformações incidiram sobre o clima organizacional, gerando maior coragem, determinação e ousadia para a tomada de decisões na biblioteca. Entretanto e apesar de esta ter se caracterizado por ser uma gestão altamente participativa no âmbito interno, com a contribuição de funcionários, professores e do próprio diretor da $\mathrm{Fa}$ culdade, faltou, talvez, envolver de forma ainda mais efetiva e direta os usuários. Cabe ressaltar, porém, que resta muito a ser feito. Seria interessante tentar conservar o mesmo ritmo de tra- 
balho, sempre com a participação de todos, procurando manter o Programa $5 \mathrm{~S}$ vivo. Considerando que esta gestão durou somente dois anos, acredito ter contribuído no que estava a meu alcance para atingir os objetivos propostos, implementando a parte inicial necessária para a futura consagração de um ambiente de Qualidade Total dentro da Biblioteca de Veterinária da UFRGS.

\section{Quality environment in an universitary library: aplication of 5S's program and a participatory style of administration}

\author{
Abstract \\ This article consists of two parts. The first \\ analyses the Administration's 5S's \\ Program, borned in Japan on the last 60s, \\ and the Participatory Style of \\ Organizational Management. The second \\ part exposes an experience in the co- \\ application of these two forms of \\ management in an Universitary Library. \\ Attemps to demonstrate that is possible, in \\ a context of escarce resources, to find \\ original solutions, reaching substantial \\ advances in the services offered to the \\ users and creating an environment of trust, \\ responsability and quality in the work \\ space.
}

\section{Keywords}

5S's Program; Participatory management; Quality environment; Library administration; Universitary library.

\section{REFERÊNCIAS BIBLIOGRÁFICAS}

1. MASIERO, Gilmar. Introdução à Administração de Empresas. São Paulo: Atlas, 1996. $149 \mathrm{p}$.

2. SILVA, João Martins de. O ambiente da qualidade na prática - 5S. 3. ed. Belo Horizonte: Fundação Christiano Ottoni, 1996. $260 \mathrm{p}$.

3. CAMPOS, Vicente Falconi. TQC: gerenciamento da rotina de trabalho do dia-a-dia. Belo Horizonte: Fundação Christiano Ottoni, 1994. 274 p.

4. OSADA, Takashi. Housekeeping, 5S's: seiri, seiton, seiso, seiketsu, shitsuke. São Paulo: IMAM, 1992. 212 p.

5. RIBEIRO, Haroldo. 5S: um roteiro para uma implantação bem sucedida. Salvador: Quality House, 1994. 79 p.

6. ROSA, Antônio Sérgio Michels; BOLSON, Cátia. Programa 5S's. Porto Alegre: FUNDATEC, [1998]. Folder

7. PRAZERES, Paulo Mundin. Minidicionário de termos de qualidade. São Paulo: Atlas, 1997. 244p.

8. CHIAVENATO, Idalberto. Gerenciando pessoas: o passo decisivo para a administração participativa. 3. ed. rev. e ampl. São Paulo: Makron Books, 1997. 257 p.

9. KANAANE, Roberto. Comportamento humano nas organizações: o homem rumo ao século XXI. São Paulo: Atlas, 1994. $99 \mathrm{p}$.

10. ALENCAR, Eunice M.L. Soriano de. Promovendo um ambiente favorável à criatividade nas organizações. Revista de Administração de Empresas, São Paulo, v. 38, n. 2, p. 18-25, 1998.

11. DIAS, Eduardo José Wense. O papel de empreendedor na gerência de bibliotecas e serviços de informação. R. Esc. Biblioteconomia UFMG, Belo Horizonte, v. 20, n. 1, p. 9-22, jan./jun. 1991.

12. MACIEL, Alba Costa. Planejamento de bibliotecas: o diagnóstico. Niterói: EDUFF, 1993. $91 \mathrm{p}$.
Agradeço muito especialmente a Denise, Eugênia, Ronaldo, Rosemeri e Tatiana, dedicados funcionários da Biblioteca da Veterinária da UFRGS, sem os quais esta experiência não teria sido possível. E a oportunidade e apoio oferecidos pelo diretor da Faculdade, Professor Carlos Marcos Barcellos de Oliveira.

\section{Nadia Vanti}

Bibliotecária da Universidade Federal do Rio Grande do Sul (UFRGS); mestranda do curso de biblioteconomia da PUC-Campinas.

E-mail: nvanti@ilea.ufrgs.br 